\title{
DONOSO ROMO, Andres. A Educação Emancipatória: Iván Illich, Paulo Freire, Ernesto Guevara e o Pensamento Latino- Americano. Tradução de Daniel Garroux e Mariana Moreno Castilho. São Paulo: EDUSP, 2020, 142 p.
}

\author{
Bruno Perozzi da Silveira \\ Doutor em Ciências Sociais \\ Universidade Estadual Paulista - UNESP \\ Araraquara, São Paulo - Brasil. \\ b.perozzi@hotmail.com
}

Para citar- (ABNT NBR 6023:2018)

SILVEIRA, Bruno Perozzi da. Resenha. Eccos - Revista Cientifica, São Paulo, n. 59, p. 1-7, e20951, jul./set., 2021. Resenha. DONOSO ROMO, Andres. A Educação Emancipatória: Iván Illich, Paulo Freire, Ernesto Guevara e o Pensamento Latino-Americano. Tradução de Daniel Garroux e Mariana Moreno Castilho. São Paulo: EDUSP, 2020, 142 p.

https://doi.org/10.5585/eccos.n59.20951.

A obra aqui apresentada foi escrita por Andrés Donoso Romo, Doutor em Ciências com menção em Integração da América Latina pela Universidade de São Paulo (USP), pesquisador do Centro de Estudos Avançados da Universidade de Playa Ancha, no Chile e professor do Centro de Pesquisas Avançadas em Educação, no Instituto de Educação da Universidade do Chile. O livro foi publicado no segundo semestre de 2020, pela Editora da Universidade de São Paulo, a Edusp, com o título A Educação Emancipatória: Ivan Illich, Paulo Freire, Ernesto Guevara e o Pensamento Latino-Americano, com a tradução de Mariana Moreno Castilho e Daniel Garroux. Pode-se afirmar que o estudo tem como principal enfoque os vínculos entre educação e transformação social a partir da análise de alguns pensadores latino-americanos: Paulo Freire, Ernesto Guevara e Iván Illich.

A obra está dividida em três partes e sete capítulos, precedidos pelos agradecimentos e pela introdução. Na Primeira Parte é realizada uma contextualização histórica do período de tensões sociais, guerrilhas e revoluções na América Latina, em específico entre os anos de 1950 e 1980, apesar de o autor traçar um panorama mais abrangente no primeiro e no segundo 
capítulo, respectivamente: As tensões contemporâneas da América Latina em perspectiva histórica e $O$ desenvolvimento em disputa na intelectualidade latino-americana.

O primeiro capítulo realiza a apresentação de uma contextualização ampla, a partir de uma interpretação das dimensões cultural, política e econômica das transformações, tensões, progressos e permanências na América Latina entre o fim do século XIX e os anos 1980. Ao realizar tal contextualização, o autor estabelece relações entre as transformações culturais, as de caráter econômico e político.

Para Donoso Romo, o início da contemporaneidade latino-americana gerou um rápido decréscimo das atividades agrícolas acompanhado pelo processo de industrialização. Esses fatores tiveram impacto direto na vida dos indivíduos, gerando uma apropriação sistemática das terras indígenas e camponesas, levando ao êxodo rural e ao crescimento urbano desordenado, alimentado pelo fluxo de camponeses e indígenas sujeitados a condições de moradia precárias e ao subemprego.

O autor parte da afirmação de que o período da década de 1950 até a de 1980 é marcado pela urbanização crescente e pela industrialização, o que leva ao aprofundamento de conflitos sociais oriundos do passado colonialista e das contradições inerentes aos processos de independência. Nesse contexto, há uma agudização de antigos problemas sociais, políticos e econômicos, como, por exemplo, a apropriação sistemática de terras indígenas e camponesas, o que leva à sujeição destes povos originários aos subempregos ou à migração para os centros urbanos. É no contexto do pós-Segunda Guerra mundial que, segundo Romo, um círculo vicioso de violência se estabelece no continente, com a eclosão de golpes de Estado e guerras internas, que levam a ascensão de regimes ditatoriais, em muitos casos de caráter militar. Nesse "círculo vicioso", destaca-se o golpe que ocorreu na Guatemala em 1954, dado que este teve "um caráter especial em decorrência da ativa participação da inteligência estadunidense. Isso permite compreendê-lo (...) como a primeira manifestação concreta da guerra fria na região" (DONOSO ROMO, 2020, p.36), abrindo todo um ciclo de intervenções e influências estadunidenses nos países latino-americanos.

Se o ano de 1954 foi marcante para as ditaduras, 1959 o foi para as guerrilhas. Pouco tempo depois dos incidentes na Guatemala, em Cuba venceu pela primeira vez um movimento guerrilheiro. Entre as principais repercussões que teve a vitória rebelde na América Latina, destacam-se: a mudança dos parâmetros do possível e do impossível (...) e a fomentação direta ou indireta, de guerrilhas por toda a região. (DONOSO ROMO, 2020, p. 37)

No segundo capítulo, $O$ desenvolvimento em disputa na intelectualidade latinoamericana, o autor apresenta algumas correntes interpretativas, produzidas pela disputa entre 
intepretações e perspectivas sobre o desenvolvimento, os caminhos e as possibilidades da América Latina frente ao recrudescimento político, representado pela ascensão das ditaduras e às possibilidades abertas pela vitória revolucionária cubana. De qualquer modo, essa efervescência política, que se agudizou após a tomada de Havana, gerou um período bastante fértil para as discussões das Ciências Sociais.

Algumas correntes intelectuais de interpretação da América Latina entram em disputa: por um lado, a partir da fundação da CEPAL (Comissão Econômica para a América Latina e Caribe) em 1948, uma vertente deu centralidade ao que se convencionou chamar de desenvolvimentismo: teorias que defendiam que, com o auxílio dos países mais ricos, os países pobres poderiam se desenvolver e até alcançar patamares próximos ou iguais das nações desenvolvidas. Por outro lado, a partir da década de 1960, outra interpretação ganha relevância, a chamada Teoria da dependência, que se configurava como um conjunto de reflexões em torno da problemática do subdesenvolvimento e sua persistência. Segundo os teóricos da Teoria da dependência, são necessárias transformações estruturais para a superação do atraso, a partir de reformas essenciais, como a ampliação do controle estatal e a reordenação do sistema social, com principal enfoque em um projeto educacional.

É partindo desses pressupostos que Donoso Romo dá início ao terceiro capítulo, Os Melhores anos da Educação na América Latina, 1950-1980, no qual, de modo geral, apresenta os processos que transformaram a educação neste período, ou seja, a ampliação do acesso à escolarização formal e o ciclo de reformas educacionais. Entre os anos 1950 e 1980 houve um aumento significativo da cobertura educacional e do acesso escolar, "enquanto em 1960 a matrícula no ensino primário não conseguia alcançar $60 \%$ da população em idade escolar, em 1985 ela superava 80\%” (DONOSO ROMO, 2020, p. 56). Tal ampliação se deu não apenas pela democratização da educação formal, mas também por sua homogeneização.

É, portanto, a partir desse momento, em que as teorias sociais buscavam compreender e afirmar as identidades latino-americanas e entender os motivos do atraso e os caminhos para sua superação, que teorias pedagógicas críticas e utópicas passam a ser produzidas. Donoso Romo apresentará, na Segunda Parte do livro, três autores, que não foram apenas importantes em sua época, mas fundaram interpretações e realizaram proposições até hoje discutidas. Iván Illich, Paulo Freire e Ernesto Guevara produziram teorias originais, diferentes entre si, mas ambas profundamente críticas aos modelos tradicionais de educação e à heterogenia produzida e reproduzida pela instituição escolar. 
No quarto capítulo, Iván Illich, a desescolarização e a Revolução Cultural, o autor apresenta a obra de Iván Illich, defendendo a tese de que o autor pode ser considerado um dos intérpretes da América Latina do ponto de vista do problema da educação e da escola.

Quando se refere a Illich, o primeiro termo que é associado a ele é desescolarização, conceito central de sua teoria pedagógica. O primeiro pressuposto do qual o autor parte é a dissociação entre educação e escola. Tal dissociação seria o primeiro passo para uma revolução cultural, em que a educação seria a força motora, da transformação total da sociedade. Mas o que levaria o Illich a defender uma ideia que, à primeira vista, parece estranha: a concepção de uma Sociedade sem escolas? Segundo Romo, devemos entender a crítica à instituição escolar de um ponto de vista mais amplo, partindo da compreensão do papel atribuído a esta instituição social tanto no campo da economia política, como no campo da ideologia. Para o autor, ao se estabelecer a confusão entre escola e educação, esta última passa para segundo plano, tendo em primeiro plano a escolarização.

A obrigatoriedade da escola se deu concomitante à colocação de uma tarefa outra: preparar os indivíduos moral, intelectual, atitudinal e ideologicamente para a inserção no modo de produção industrial. Desse modo, mais do que mera reprodutora, a escola é, pela obrigatoriedade e pela confusão entre formação e escolarização, promotora de opressão, responsável por “produzir bons consumidores” (DONOSO ROMO, 2020, p. 77)

Como Donoso Romo apresentara nos dois primeiros capítulos, nos anos 1960 e 1970, a perspectiva da revolução toma centralidade na América Latina, sendo leitmotiv nas discussões teóricas. Nesse contexto, diversos intelectuais buscam compreender tais possibilidades e os caminhos para a sua concretização. Illich toma para si a tarefa de encontrar, apontar e seguir por uma alternativa revolucionária, cujo epicentro seria o terceiro mundo. Segundo o autor, este é o ponto central da proposição illichiana, ou seja, a possibilidade inerente à educação de transformar não apenas o aspecto formativo, mas a sociedade como um todo, superando as formas opressivas de sociabilidade em nome de uma forma emancipatória, a convivencialidade.

Assim, a desescolarização seria a força motora desta transformação, que teria como ato inaugural a formação de "redes educacionais", não hierárquicas, em que cada um contribuiria com aquilo que pudesse, se aproximando, como demonstra Romo, do que Freire defendia, na mesma época, no Brasil.

Já no quinto capítulo, Paulo Freire, o Pensamento Latino-Americano e a Luta pela Libertação, Donoso Romo traça uma análise do pensamento freireano a partir de quatro eixos interpretativos, o processo de alfabetização do próprio autor, sua proposta de alfabetização, o 
estabelecimento de seu pensamento e o movimento intelectual e prático que propunha a construção de uma nova sociedade e, por fim, as relações entre relação e a luta revolucionária.

Ao buscar a compreensão das contribuições da teoria pedagógica freireana no contexto latino-americano, o autor realiza um caminho biográfico e histórico, desde as experiências da infância de Freire com sua família, passando pelo projeto de alfabetização de adultos em Angicos, no Rio Grande do Norte, base para sua perspectiva de educação popular, em consonância com as proposições da teologia da libertação.

Ao abordar a obra do educador brasileiro, Donoso Romo a interpreta no contexto de ascensão das ditaduras militares da América do Sul, acompanhando a atuação de Freire durante o governo progressista de João Goulart, bem como a perseguição sofrida após o golpe militar de 1964, que o levou ao exílio no Chile.

É no durante seu exílio no país andino que, segundo Romo, Freire desenvolve, de modo mais acabado, suas ideias sobre educação e prática política e, de certo modo, sobre os problemas sociais da América Latina.

Fruto dessas reflexões, a "Pedagogia do Oprimido" tem boa recepção, por se ancorar em experiências concretas, por seu direcionamento "aos deserdados do mundo" (ROMO, 2020, p.97), por sua por sua escrita militante, que atribua o papel de conscientizar e mobilizar os oprimidos para a superação da situação opressora. Por fim, ainda acompanhando o percurso trilhado por Freire, Donoso Romo se debruça sobre a pedagogia da esperança, sobre as proposições do educador após sua saída do Chile, em 1969, e sua ida para Harvard, nos E.U.A.

A conclusão de Donoso Romo, ao refletir sobre as relações possíveis entre a obra de Freire e as lutas revolucionárias, é a de que o papel de conscientização da educação não é, em si, um aspecto revolucionário, mas um apoio indispensável aos processos revolucionários. Toda revolução, segundo Romo, tem um trabalho cultural libertador que a acompanha e a Educação Popular, a pedagogia do oprimido e da esperança, seriam parte importante deste trabalho cultural.

No sexto capítulo, último da Segunda Parte, intitulado Ernesto Guevara e o Papel da Educação nos Processos revolucionários, neste capítulo, abordagem se dá de um modo um pouco distinto, já não se trata de estabelecer relações entre teoria pedagógica e praticas revolucionárias, produzidas por agentes e em contextos distintos, trata-se de compreender as proposições para a educação de um revolucionário, Ernesto Guevara, e a tentativa de colocar tais proposições em prática em pleno processo revolucionário.

Donoso Romo acompanha o percurso do revolucionário argentino, dando especial atenção aso seus escritos sobre educação. No entanto, a questão, que é mote de toda a obra, 
aparece com centralidade naquele primeiro de janeiro de 1959, ou seja, qual seria, no contexto da Revolução Cubana, o papel da educação? Um ponto central a ser abordado era a interpretação do próprio processo revolucionário estabelecida por Guevara. Para ele, "o socialismo econômico não lhe interessava se ele não estivesse acompanhado de uma moral comunitária" (DONOSO ROMO, 2020, p. 115). Assim, ao tomar como indissociável a luta contra a miséria e a luta contra a alienação, Guevara coloca a educação no centro dos processos de transformação social.

\footnotetext{
No caso da Cuba revolucionária, um dos primeiros indicativos visíveis da relevância que adquiriu a educação pode ser rastreado quando, após poucos meses da vitória rebelde, todas as fortalezas militares começaram a ser transformadas em escolas. (DONOSO ROMO, 2020, p. 116)
}

Donoso Romo aponta outros exemplos desta centralidade da educação no processo revolucionário, talvez, o mais emblemático deles seja a "Campanha de Alfabetização", que teve início em 1961 e durou até 1975. Essa campanha expressa, segundo o autor, um "primeiro passo para acabar com as diferenças entre o povo e a vanguarda" (DONOSO ROMO, 2020 p.117). Essa práxis educativa, ativa e revolucionária, foi levada por Guevara por onde passou, em suas contribuições em processos de sublevação e revolução na América e África. De certo modo, sua pedagogia adotou o intuito de, pela educação, transformar as pessoas em revolucionárias,

Devia-se transformar toda a sociedade em uma grande escola preocupada em induzir, por meios racionais, o tão almejado empenho que se conseguia através do apelo emocional. (DONOSO ROMO, 2020, p.122).

Essa mobilização total da sociedade revolucionária, mediada e motivada pela educação, foi denominada por Guevara como "autoeducação".

Na Terceira Parte e sétimo capítulo, intitulado Educação e Transformação Social no Pensamento Latino-Americano, Donoso Romo retoma os principais aspectos da obra, as teorias pedagógicas mobilizadas, estabelecendo relações entre elas, de modo a apresentá-las como reflexões complementares, fruto de um contexto de conturbações sociais, mas que podem ser trazidas para a atualidade.

A obra de Donoso Romo apresenta uma reflexão de suma importância por motivos diversos: por apresentar ao leitor brasileiro uma história da América Latina de um ponto de vista da práxis e da epistemologia, ao tomar as lutas revolucionárias, revoluções e contrarrevoluções como fio condutor, aproximando e relacionando os diferentes contextos com teorias pedagógicas produzidas. A escolha das teorias de Illich, Freire e Guevara corroboram com sua tese, já que as teorias /tratam de propostas que, apesar das diferenças marcantes, 
encontravam na educação um meio de conscientização quanto à opressão e dominação, e, ainda mais, propunham que a educação é prática transformadora e emancipatória, não como complemento dos processos revolucionários, mas como cerne e força motora desses processos. A leitura de A educação Emancipatória nos leva a uma reflexão sobre nós mesmos, sobre as opressões que marcam nossa história, mas também sobre a resistência e luta contra essa opressão. Apresenta a educação como caminho a ser trilhado para a transformação qualitativa das sociedades.

\section{Referências}

DONOSO ROMO, Andres. A Educação Emancipatória: Iván Illich, Paulo Freire, Ernesto Guevara e o Pensamento Latino-Americano. Tradução de Daniel Garroux e Mariana Moreno Castilho. São Paulo: EDUSP, 2020. 142 p.

SILVEIRA, Bruno Perozzi da. Educação Zapatista como Utopia Concreta. 2020. $231 \mathrm{f}$. Tese (Doutorado em Ciências Sociais) - Universidade Estadual Paulista, Araraquara-SP, 2020. 